\title{
Empoderamiento juvenil y control policial informal*
}

\author{
Luis Gerardo Gabaldón ${ }^{* *}$
}

\section{Resumen}

El artículo discute la aplicación de mecanismos altamente coactivos de control social informal sobre la población juvenil percibida como desviada o incluso rebelde, utilizando como marco referencial la noción de vulnerabilidad vinculada a carencias asociadas a la indefinición de identidades, la atenuación de controles informales benignos, la insuficiencia o ineficacia del control social formal, las debilidades socioeconómicas y la exclusión social. Los datos empíricos provienen, fundamentalmente, de estudios y diagnósticos venezolanos de las últimas dos décadas, contextualizados dentro de la perspectiva internacional sobre la vulnerabilidad juvenil. Se sugieren mecanismos para reducir la aplicación de la coacción informal con base en el empoderamiento juvenil asociado al incremento de la respetabilidad y reconocimiento de identidades legítimas, particularmente frente a la policía que, como agencia de control social con amplias facultades de intervención situacional, estaría mayormente propensa a aplicar medidas informales altamente coactivas para lograr su afirmación frente al desafío y obtener sometimiento.

\footnotetext{
* Artículo recibido el 9 de Abril de 2015. Aceptado el 9 de Julio de 2015.

** Profesor Titular de Derecho Penal y Criminología Universidad Católica Andrés Bello. Caracas. Venezuela. Correo electrónico: luisgerardogabaldon@gmail.com
} 


\section{Palabras clave}

Control social informal - violencia policial - delincuencia juvenil.

\section{Abstract}

The article approaches highly coercive informal social control towards youngsters perceived as deviant or rebels, using as a framework vulnerability related to unstable identity, weak of traditional informal soft control and legalistic non violent formal control, socio economic stress and social exclusion. Data come mostly from Venezuelan studies along the last two decades, contextualized within the international and Latin American discussion on juvenile delinquency and social control. Discussion is carried about mechanisms to reduce informal violent coercion through juvenile empowerment, by increasing respectability and legitimate identity recognition, particularly facing the police, which is prone to informal highly coercive social control for gaining submission and for expressive affirmation of authority.

\section{Keywords}

Informal social control - police brutality - juvenile delinquency.

\section{Los jóvenes entre el control social formal e informal}

Los jóvenes representan blancos atractivos de formas extensas e intensas de control social debido a su dependencia de los adultos, a la indefinición de su identidad laboral y profesional y a la rebeldía que implica su transición hacia la edad adulta. Al mismo tiempo, la juventud genera desafío a lo establecido y cuestionamiento de valores tradicionales y figuras de autoridad, propios del relevo generacional. El sometimiento y desafío han existido seguramente en todas las culturas y épocas, aunque probablemente hoy se manifiesten con mayor visibilidad debido a la fragmentación de las estructuras de dominación patriarcal y a la desvinculación precoz de sistemas de inserción legítima, productos de la urbanización, la informalización y desregulación económica, la marginalidad y la deslocalización de los vínculos sociales.

Por lo que se refiere específicamente a la relación entre la policía y los jóvenes, ella implica un desbalance de poder a favor de la policía. Como ha sostenido Black (1980) en un estudio clásico sobre el desempeño policial, la sujeción juvenil a formas relativamente más intensas de control social, tanto familiar como extra familiar, determina una percepción de carencia (no en vano se utiliza el vocablo adolescencia) que conduce a un mayor ejercicio de la coacción en situaciones de confrontación y desafío, propias de esta etapa de vida. Los estudios empíricos sobre la interacción entre la policía y el público sugieren un incremento de la coacción policial en la medida en 
que se incrementa la hostilidad y resistencia de los sujetos pasivos de control (Pilliavin y Briar, 1964; Gabaldón y Murúa, 2010; Gabaldón y Serrano, 2001). Esta resistencia, en el caso de los jóvenes, se encuentra potenciada por la rebeldía y desafío propios de su edad.

La asociación entre adolescencia y delincuencia, independientemente de cuál de ellas se adopte como variable dependiente y de los métodos y formatos de registro, ha sido bien documentada por la investigación (West, 1984: 86-87; Hagan, 1989: 145 ss.; Brown, Esbensen y Geis, 1991: 190; Gottfredson y Hirschi, 1992: 124 ss.; Farrington, 1996: 257 ss. Garrido, Stangeland y Redondo, 2001: 289-292; Birkbeck, 2006), y por ello los jóvenes se encuentran ampliamente representados en los registros delictivos. En esta representación influyen no solo la disposición a actuar, sino la vulnerabilidad frente a la detección y el procesamiento judicial. Precisamente dicha vulnerabilidad, en cuanto implica sujeción a agencias de control social formal que operan dentro de un marco jurídico, ha sido expresada como una situación donde la distancia y la subordinación determinarían la aplicación de "mayor cantidad de Derecho" (Black, 1989: 8-11). Como la policía puede operar también al margen del sistema penal oficial, el incremento de la coacción podría ser concebido como "menor cantidad de Derecho", desde un punto de vista legalista, aunque no disminución de la intensidad del control. Los castigos extremos aplicados por la policía, incluyendo las ejecuciones extrajudiciales, pueden ser concebidos, de este modo, como incremento de un control social informalizado de carácter maligno, esto es, con elevados niveles de coacción.

Este ensayo apunta al análisis de la vulnerabilidad de los jóvenes como sujetos pasivos de control social y a la proposición de un marco para propiciar una reducción de la violencia en torno al concepto de empoderamiento juvenil. Este concepto se vincula con el incremento de la respetabilidad moral y el poder de reclamo social de un segmento etario (15-24 años) que constituye un quinto de la población venezolana actual y que se encuentra sometido a formas cada vez más intensas y violentas de control social informal. Los datos provienen básicamente de dos estudios que utilizaron entrevistas y registros de tipo cualitativo sobre percepciones de la población juvenil en Venezuela, uno vinculado al uso de las armas de fuego entre jóvenes transgresores recluidos en dos centros de detención juvenil de Caracas, durante 1998, y otro que analizó, mediante grupos focales, encuentros entre policía y jóvenes, con ocasión de los diagnósticos adelantados por la Comisión Nacional para la Reforma Policial, en 2006. Mediante el primer estudio se aplicaron 203 cuestionarios en dos centros de internamiento, que comprendieron el $97 \%$ de la población juvenil internada, de los cuales 83 (40\%) corresponden a entrevistas personalizadas, sobre las cuales se basan los extractos y comentarios abajo comentados. Estos jóvenes, cuya moda etaria fue de 17 años, se encontraban a disposición del tribunal de menores por robo en un 27,2 \%, infracciones vinculadas a las drogas en un 23,3 \% y homicidio en un 21,6 \% (Gabaldón y Serrano, 2001). Mediante el segundo estudio se analizaron las respuestas en dos 
grupos focales de discusión, uno de los cuales se llevó a cabo con 5 jóvenes de clase media alta, con edades entre 16 y 17 años, y otro con 7 jóvenes provenientes de sectores populares, con edades entre 13 y 20 años (Gabaldón y Peraza, 2007). Las entrevistas y las intervenciones en los grupos de discusión fueron transcritas, determinándose temas y comentarios recurrentes sobre la aplicación de la fuerza, medidas coactivas legales o ilegales y constancias y discrepancias entre diversos segmentos de los jóvenes estudiados.

Si bien es posible que se hayan producido algunos cambios en la forma de abordar a los jóvenes por parte de la policía, luego de la aprobación de las nuevas leyes de policía a partir de 2008 (Gabaldón, 2013), ellos han incidido fundamentalmente en la aprobación de nuevos protocolos e instructivos antes que en prácticas cotidianas, la cuales no muestran variación dramática documentada por la investigación y que, por otro lado, resultan resistentes a la modificación debido a la cultura corporativa, a la inercia organizacional e, incluso, a la creciente militarización en la prestación del servicio policial (Antillano, 2012; Sanjuán, 2013). El uso desproporcionado de la fuerza parece haber descendido desde 2008 entre las policías uniformadas venezolanas, aunque no en el Cuerpo de Investigaciones Penales, Científicas y Criminalísticas (Provea, 2013).

\section{Control social informal y aplicación de la coacción}

El común denominador del control informal, en cualquiera de sus variantes, está dado por lo inespecífico de las facultades con que cuentan las agencias de control y por el carácter blando o fácilmente removible de las etiquetas aplicadas (Gabaldón, 1990). Aunque en la literatura latinoamericana la distinción entre ambas modalidades de control opera con base en la doble dicotomía estatal-coactivo para lo formal y privadoinductivo para lo informal, de vertiente althusseriana en cuanto a la distinción entre aparatos represivos e ideológicos del Estado (ver Gabaldón, 1982: 18-21), la investigación empírica reciente en América Latina muestra gran fluidez entre la coacción sometida a reglas sustantivas y procedimentales y la ajena a dichas formalidades entre agentes estatales de control social (Cano, 2001, Figueroa Ibarra, 1991, Monsalve Briceño, 2005). Por ello el rasgo distintivo entre lo formal y lo informal, para que el concepto resulte más productivo desde el punto de vista teórico y explicativo, requiere un replanteamiento en cuanto al marco normativo de ejercicio y el impacto subsiguiente de las etiquetas aplicables, más allá de la adscripción estatutaria de sus agentes. Esto quiere decir que el control informal estará presente entre agentes estatales si actúan obviando procedimientos y mediante acciones con registros delebles, por más violentas que resulten. Estas intervenciones pueden comprender una gama muy variada de conductas y asumir distintos grados de intensidad, dependiendo de la distancia entre las partes involucradas, del sometimiento de los sujetos pasivos de 
control, del refuerzo de la audiencia circundante y de la percepción sobre la eficacia y la suficiencia de la intervención.

El desarrollo del control social informal, al menos dentro de las estructuras nacionales organizadas bajo la forma de estados, supone, de alguna manera, una contracción de los espacios del control formal, que podría estar reforzada por la descalificación de este último bajo argumentos de autoritarismo, ritualismo o estigmatización. Esta contracción es proclive a generar intrusión y vigilancia extensas en caso de homogeneidad cultural y aceptación colectiva, mientras, en caso de heterogeneidad cultural y resistencia manifiesta, coacción sin procedimientos. Estas últimas condiciones podrían ser más recurrentes en el medio urbano, aun dentro de un país sin grandes diferencias culturales, debido a la diversidad de los estilos de vida y a la disminución de los controles primarios (Gabaldón, 1987). En efecto, respecto a los jóvenes de las grandes ciudades, considerando su rebeldía natural, su escasa capacidad de reclamo social, sobre todo cuando se trata de la población perteneciente a los grupos más pobres, y el debilitamiento de los mecanismos de supervisión y control parental, la informalización del control tiende a asumir formas de extrema coacción, matizadas por tácticas de negociación y aprovechamiento oportunista. En el caso de Cali, Colombia, cuando se concertaron acuerdos de entrega de armas y reintegración comunitaria de jóvenes pandilleros, en 1993, en el plazo de los 5 años siguientes casi el $25 \%$ de los jóvenes participantes resultaron muertos, en muchos casos con intervención directa de la policía (De Roux, 2001). Para El Salvador se ha sugerido que grupos de pandilleros podrían ser utilizados por empresarios lícitos como herramientas para socavar la competencia comercial, aprovechando habilidades desarrolladas por aquéllos dentro de la ilegalidad, con la ventaja de la contratación informal y a bajo costo (Aguilar, 2010). Estos ejemplos ilustrarían las negociaciones entre agentes estatales o privados con sujetos pasivos de control que no conllevan tratos equitativos que permitan reducir la violencia, antes bien, contribuirían a perpetuarla, bien mediante refuerzo de prácticas ilícitas, bien mediante la alienación frente a mecanismos que traicionan la confianza que deberían generar el Estado y los mercados legales.

\section{Debilidades del control social formal sobre los jóvenes: el sistema de justicia penal}

En una investigación adelantada sobre posesión y actitudes vinculadas a las armas de fuego entre jóvenes venezolanos, se determinó que estos manifestaron percepciones de indulgencia o ineficacia de los mecanismos legales, específicamente jurisdiccionales, para enfrentar las prácticas y consecuencias del uso de armas de fuego, al parecer relativamente extendidas para 1998, fecha del estudio. Entre el $68 \%$ y el $62 \%$ de los encuestados estimó muy bajo o nulo el riesgo de ser detenidos en caso de porte, exhibición pública e, incluso, disparo de armas de fuego y el 42 \% estimó también muy bajo o nulo el riesgo de detención en caso de producir heridas o muertes con dichas 
armas (Gabaldón y Serrano, 2001). El seguimiento de 79 casos identificados por la policía como de porte de armas de fuego, entre 1996 y 1997, permitió determinar que el $58 \%$ no fue remitido al tribunal, quedando sin actividad judicial alguna, mientras que de los 33 casos ingresados al sistema judicial, solo 17 concluyeron con una medida definitiva, custodia paterna o libertad vigilada. Estos resultados implican que no solamente el riesgo percibido de ser procesado por el porte y el uso de las armas de fuego es bajo, sino que solo poco más de la quinta parte de los casos detectados por la policía llegan a una decisión en sede judicial, que constituiría el espacio del control formal indicado para sancionar la conducta en cuestión (Gabaldón y Serrano, 2001). Por ello se podría considerar que la activación del control social formal en esta materia es escasa. Una evaluación posterior sobre la mitad de las Fiscalías del Sistema de Responsabilidad Penal del Adolescente del área metropolitana de Caracas permitió determinar que el $82 \%$ (2000) y el $72 \%$ (2001) de todos los casos conocidos a nivel policial permaneció fuera del sistema judicial, sin que el fiscal solicitase la remisión, el sobreseimiento o la acusación (Moreno Zapata, 2002). Por otra parte, una investigación cualitativa entre 27 operadores del Sistema de Justicia Penal del Adolescente y 27 adolescentes procesados en sede penal, adelantada entre mayo y junio de 2005, permitió concluir que entre los jueces, fiscales y defensores del Área Metropolitana de Caracas apenas se reconoce la capacidad de los adolescentes de asumir las consecuencias de sus actos y que los infractores consideran inefectivas las medidas cautelares sustitutivas al encierro para contener su conducta delictiva, eludiendo la presentación periódica bajo diversas razones, algunas banales, como fastidio u otros problemas (Serrano, Perfetti y Martínez, 2010: 113 y 115). Si a ello se añade que, según los datos de la Encuesta Nacional de Victimización y Percepción de Seguridad Ciudadana de 2009, el $60 \%$ de los robos es atribuible al grupo etario entre 15 y 24 años de edad, y el $74 \%$ de todos los robos son cometidos con armas de fuego (Venezuela, 2010), tendríamos claros indicios de que los mecanismos formales de control social frente a los jóvenes delincuentes en Venezuela son bastante laxos e ineficaces.

El control social formal sobre los jóvenes, representado fundamentalmente por el sistema de justicia juvenil, pareciera enfrentar severas fallas para ocupar su espacio. Si bien en el estudio sobre jóvenes y armas de fuego de 1998 se encontró una correlación positiva estadísticamente significativa entre el número de expedientes judiciales levantados y la frecuencia del uso del arma contra otra persona $(.28, p=.003)$, la frecuencia de los disparos efectuados $(.27, p=.001) \mathrm{y}$, sobre todo, la frecuencia de las detenciones policiales (.60, $\mathrm{p}<$.0001) (Gabaldón y Serrano, 2001), ello no indicaba una activación eficiente frente a cada episodio por parte de los mecanismos de control formal, sino una intervención acumulativa, seguramente tardía, en función de la reiteración de la conducta. Todo esto sugiere que la respuesta dentro del marco legal a infracciones graves cometidas por los jóvenes es débil y diferida en el tiempo, lo cual 
promueve un sistema de control informal que no es benigno, en el sentido que opera por medios altamente coactivos y con participación directa de la policía.

\section{La policía y el control informal maligno frente a jóvenes transgresores}

La policía no es percibida por los jóvenes transgresores del estudio de 1998 como una instancia formal de control que opera con reglas de derecho. En cuanto a la coacción explícita y directa, ella no es considerada como producto del ejercicio de la autoridad con miras a la restricción, contención y traslado a otra instancia de decisión, sino como la aplicación de un castigo directo, que no requiere un procedimiento judicial. De este modo, el policía se convierte en el agente de un castigo situacional, inmediato y terminal. Algunos relatos abonan esta interpretación:

"Los policías me agarraron robando un carro, me llevaron a Altamira por un puente y me querían matar, me dieron un cachazo [golpe con el mango de la pistola] y una pela [golpiza] y me dejaron allí todo morado" (Serrano, 1999, entrevista 64).

"Martillé [extorsioné] a una mujer que resultó ser policía, le rayé el carro, salió, me paró y me disparó en el hueso y me salió por detrás de la nalga. La metropolitana la detuvo y estuvo presa" (Serrano, 1999, entrevista 119).

"Atraqué a un turista y un guardia me agarró y me disparó" (Serrano, 1999, entrevista 196).

"Me agarró la Metropolitana, me guindaron [colgaron] de una viga con las esposas y un colchón enrollado dándome batazos [golpes con bate de beisbol]. Estuve 3 días detenido en Dirección de Menores en Coche. A cada rato venía un policía. La PTJ es la peor policía, la que más maltrata. La menos mala es la Metropolitana porque no lo golpea tanto a uno" (Serrano, 1999, entrevista 199).

"La policía cuando me arrestó, me sacaron de mi casa y me cayeron a cachazos, me acusaron de golpear al muchacho con quien mi hermano peleó" (Serrano, 1999, entrevista 202).

En algunos supuestos, la policía es percibida como concedente del poder de castigo a un tercero a quien se le reconoce dicha prerrogativa, generalmente la víctima. En estos casos, el titular legitimado para aplicar la coacción legal asocia a otros o delega en ellos la facultad de aplicar la coacción extralegal. Los siguientes relatos expresan estas propiedades del control delegado en forma de castigo: 
"Los policías les dan armas a los malandros [delincuentes] para que maten por ellos y no ensuciarse... Malandro cartelado, "el que manda en el barrio", la policía prefiere que lo maten. Los policías venden armas a los chamos para que maten a otros" (Serrano, 1999, entrevista 100).

"La PTJ [policía judicial] me maltrató con cadenas, bates, palos de pico, crucificado, golpes y patadas, los familiares se transearon (sic) [se pusieron de acuerdo] para golpearme. Me querían llevar a lincharme en una plaza construida por los vecinos, donde falleció el occiso... pero me salvó una mujer policía. Tengo quistes y traumatismo en el riñón derecho y la Fiscalía no hizo nada porque no sabe quiénes me golpearon más, si los familiares del occiso o los policías" (Serrano, 1999, entrevista 203).

En todo caso, el control en forma de castigo no es indiscriminado, fundamentalmente por cuanto puede acarrear consecuencias negativas para el funcionario policial, bien exponiéndolo a sanciones disciplinarias o penales, bien a represalia directa por parte de quien es sujeto pasivo de control. En este sentido emergen variables vinculadas a la inmunidad relativa de los funcionarios y a la capacidad de reclamo de las víctimas, que, como se ha destacado en otro lugar (Gabaldón y Birkbeck, 1996, 1998), son relevantes para explicar el uso de la fuerza por parte de la policía. Los siguientes relatos ilustran bien el argumento:

"Disparan a matar cuando son comisarios, de sargento para arriba, porque si no, los menores [jóvenes transgresores] los matan. Los menores disparan a matar. Los rasos [rangos bajos] no disparan para no meterse en problemas, esto no pasa con los mayores de edad a quienes matan fácilmente" (Serrano, 1999, entrevista 69).

"[Las armas] las llevan o cargan dentro del barrio, no afuera porque los agarra la policía a menos que sea un malandro arrecho [delincuente atrevido]" (Serrano, 1999, entrevista 101).

"Disparan cuando no tienen el uniforme" (Serrano, 1999, entrevista 111).

Los comentarios que anteceden permiten suponer el establecimiento de un sistema de control informal, con gran intensidad en el uso de la coacción, auto atribuido por parte de la policía, no sometido a escrutinio por las restantes agencias formales de control social ni por el público, que se ejercita mediante una combinación de criterios pragmáticos y reglas no jurídicas, que podrían denominarse "reglas tácticas" (Gabaldón y Birkbeck, 1998), lo cual confiere a la policía un poder de castigo inmediato, más allá del poder coactivo requerido para someter y consignar al infractor a la agencia de control social que, conforme al ordenamiento jurídico, tiene competencia para aplicar 
el castigo legal. Si bien estas formas de castigo policial han sido descritas para infractores en general (Monsalve Briceño, 2005), la operación de este sistema de control informal en el medio juvenil, en particular el relativo a los jóvenes pobres, con carencias que incluyen la deserción escolar y la falta de estructura familiar de soporte y protección, sugiere una vulnerabilidad particular de los jóvenes frente a la coacción, no solamente la vinculada a sus relaciones entre pares, sino la que se produce como consecuencia de la adopción de medios altamente coactivos de control social por parte de los agentes del Estado y frente a la cual los mecanismos de protección y defensa se encuentran minimizados.

\section{Exposición de jóvenes según condición socioeconómica}

Dentro de la amplia consulta emprendida por la Comisión Nacional para la Reforma Policial en Venezuela durante 2006 se planteó un estudio de grupos focales con sectores en situación de vulnerabilidad y riesgo en los encuentros con la policía. El objetivo fue determinar, mediante un análisis de tipo cualitativo, qué tipos de encuentros, experiencias y expectativas surgían entre policías y ciudadanos en situaciones cotidianas de interacción. Dos de dichos grupos focales jóvenes de clase media y alta, seleccionados en colegios privados, y jóvenes provenientes de sectores populares seleccionados por operadores sociales en barrios de Caracas.

Los tipos de encuentros y experiencias reflejan la estratificación social, tendiendo las acciones policiales a ser más intensas respecto a los miembros de los sectores populares que respecto a los sectores de clase media y alta, si bien estos últimos no están exentos de hostigamiento. Estos últimos reportan encuentros donde existe tirantez y roce de baja intensidad, como reflejan los siguientes comentarios:

M3: "El otro día yo estaba en una plaza pública, con uno de los del gobierno municipal juvenil y vinieron dos Policías a lo macho... vamos a decirlo así, a sacar a todo el mundo de la plaza..."fuera, fuera, ya váyanse pa' su casa, son las 9 vayan a dormir, no pueden estar aquí", o sea, la plaza es de usos públicos, la gente la puede utilizar y ellos no le pueden decir a la gente, que la mayoría eran adolescentes y niños que estaban jugando, privarlos de su derecho de diversión y recreación" (Gabaldón y Peraza, 2007: 459).

M1: "... nosotros estábamos tranquilos bajando de mi casa y dos patrullas nos tocaron... "¿Ustedes viven por aquí?", y nosotros sí, o sea, si no es porque andábamos con dos mujeres nos pegan contra la pared y nos piden la cédula, y todos éramos menores de 18 años, o sea, hay que tener conciencia de que uno tiene sus derechos, o sea, ¿y si yo no vivo por ahí?, ¿y si yo soy un simple ciudadano que está caminando? Las calles son públicas, podemos circular todos, eso es un derecho que a nosotros nos tienen que garantizar y no violentar, es muy importante eso" (Gabaldón y Peraza, 2007: 459-460). 
Los jóvenes de sectores populares, por el contrario, tienden a reportar encuentros donde la policía manifiesta mucha más intensidad y maltrato, como se desprende de los siguientes comentarios:

M3: "Yo estaba en un operativo...o sea... a mí me agarraron en un operativo... [Risas]... no, yo no soy de esos, sino que... ¿sabe? A mí me gusta esta... disculpe... en ese tiempo yo estaba muy enamorado. Entonces, yo había dejado a mi novia en su casa, y yo me voy caminando, entonces me agarraron, tenía el uniforme de una institución pues, tenía mi carnet y todo. Ellos me agarraron y me agredieron, o sea, eso tampoco me gusta, porque me dejaron dos horas en la jefatura, o sea, cosas que no debería hacer un policía...agredir...Y de paso vejar a uno con un carnet que dice que eres estudiante" (Gabaldón y Peraza, 2007: 468).

M7: "En el liceo, fue lo más desastroso que hubo ahí, pasó de todo, llegó la Policía, porque estaban irrespetando el liceo, estaban con las instalaciones... bajando de la azotea. El trato de los policías fue como de un gorila endemoniado, estaban como empujándolo a uno, metiéndose de aquí para allá... contra las casas" (Gabaldón y Peraza, 2007: 469).

M4: "Una vez me agarraron unos policías, y me llevaron a sanador [con castigos] bastante fuerte, o sea, el trato que recibí allá, siendo menor de edad, que tiene uniforme, el maltrato que me dieron, la jaloneadera [arrastrando] para allá y para acá, las esposas que no me las merecía, y no eso, sino que a las demás personas que estaban ahí, que no las trataban humanamente, sino que como unos animales golpeándoles y ¿sabes?, como les daba la gana" (Gabaldón y Peraza, 2007: 469).

Como se puede apreciar, si bien la condición juvenil puede definirse como de vulnerabilidad frente a la conducta policial, en el sentido que los jóvenes se encuentran en proceso de definición de identidades, carecen de estabilidad laboral e ingresos y, en general, están sometidos a la autoridad de otras personas, la situación de pobreza acrecienta dicha vulnerabilidad, que se traduce en un mayor empleo de la coacción. Tal empleo, como lo demuestran los comentarios antecedentes, no guarda relación con el uso instrumental de la fuerza, esto es, ella no se aplica con la finalidad de obtener un sometimiento frente a la resistencia juvenil o para impedir la comisión de un delito, sino que implica un uso expresivo, esto es, tendente a afirmar la identidad del policía, en estos casos, autoritaria frente al adolescente $y$, como demuestran muchos otros ejemplos, a aplicar un castigo directo por una falta real o supuesta. Es la modalidad e intensidad del uso de la fuerza lo que varía, de acuerdo al estatus social, vinculado al poder de reclamo del sujeto pasivo (Gabaldón y Birkbeck, 1998, 1996), si bien, en 
general, la disposición a utilizarla, fuera del marco de lo estrictamente necesario como contención, frente a los jóvenes, parece ser una conducta policial bastante extendida.

\section{Control policial juvenil: entre la desconfianza de la formalidad y la informalidad de la fuerza}

Los resultados de evaluaciones sobre la percepción ciudadana del sistema de control social formal en Venezuela sugieren, en general, desconfianza y falta de credibilidad. Sanjuán (2000) refiere datos de una encuesta adelantada en Caracas en 1998 bajo el patrocinio del Programa de Naciones Unidas para el Desarrollo, según la cual $85 \%$ de los encuestados manifestó poca confianza en el sistema judicial y 49,9\% estaba dispuesto a buscar justicia por sus propias manos. En la encuesta de victimización encomendada en 2001 por el Ministerio de Justicia a la empresa Consultores 21, el cambio de las leyes penales y el poder judicial fueron percibidos como de relativa poca importancia para la regulación del control social formal, aunque la relevancia atribuida a dichos cambios fue ligeramente más alta para las personas más afluentes $(15,5 \%$ y $21,4 \%)$ que para las personas más pobres (11,1\% y $10,5 \%)$, respectivamente (Consultores 21, 2001). Ello podría indicar que para los menos favorecidos el control formal es más lejano e inaccesible, siendo que su posición como sujetos activos de derechos y reclamos es más precaria. La Encuesta Nacional de Victimización de 2006 permitió determinar que algo más del $54 \%$ de las víctimas de delitos se abstuvo de denunciar porque la policía no tomaría la denuncia o no haría nada con ella, mientras un 12 \% no denuncia por temor a represalias (Gabaldón, Benavides y Parra, 2007). Por otro lado, las percepciones mayormente asociadas a la policía, con ocasión de los encuentros con los ciudadanos, son de prepotencia y negligencia (Ibídem). Según los datos de la Encuesta Nacional de Victimización y Percepción de Seguridad Ciudadana de 2009, las tasas de victimización por homicidios y lesiones ejecutados por la policía podrían ser mucho más elevadas que las correspondientes a toda la población, mientras el $16 \%$ de los encuestados consideró que la policía actúa de ordinario con violencia, el $19 \%$ con maltrato y el $33 \%$ con prepotencia (Venezuela, 2010). Todo ello sugiere elevados niveles de coacción empleados por la policía, que cuando se manifiestan frente a los jóvenes, podrían incrementarse por la condición de vulnerabilidad propia de la edad, condición socioeconómica y percibida carencia de respetabilidad moral, si se trata de jóvenes infractores.

Una revisión de los encuentros entre la policía y los jóvenes que concluyen en muertes en Venezuela revela la recurrencia del castigo extremo aplicado por dicha agencia, más allá de la necesidad de neutralizar un comportamiento en curso. De los 28 casos reportados por Provea, entre octubre de 2000 y septiembre de 2001, como de violación del derecho a la vida cuyas víctimas fueron adolescentes, solo 3 de ellos podían ser atribuidos a situaciones de confusión y uso indiscriminado de armas de fuego con víctimas no designadas; dieciocho casos, es decir, cerca de las dos terceras 
partes, corresponden a ejecuciones vinculadas a venganzas de la policía por hechos anteriores y seis casos corresponden a castigos como consecuencia de robos infraganti o muy recientemente cometidos (Provea, 2001). En un caso extremo, pero ilustrativo de la imposición del control en una situación límite, frente a la resistencia a obedecer una orden de disminuir el volumen de la música que escuchaba, funcionarios policiales detuvieron al adolescente de 15 años, disparándole a los brazos y estómago, simulando luego un enfrentamiento con un arma detonada por su propia mano (Provea, 2001). En el Informe de Provea correspondiente al periodo octubre 2005septiembre 2006 fueron registrados 169 casos de ejecuciones extrajudiciales, de las cuales 17 (10\%) corresponden a jóvenes varones entre 15 y 17 años de edad. En algunos de los casos se pudo determinar la delegación de la ejecución a cargo de un tercero, el móvil de la venganza por un agravio de naturaleza pasional y la aplicación reiterada de maltratos conducentes a la muerte (Provea, 2006).

Probablemente estos datos reflejan la culminación de una escalada de agravios de diversa naturaleza que ilustra la apropiación policial del castigo directo como control social. Las situaciones donde se puede excluir el móvil estrictamente personal de la retaliación, podrían ser interpretadas como eventos en los cuales la policía se arroga y asume el poder de castigar como una forma extrema de control social, desplazando los procedimientos formales para la aplicación del castigo legal. La investigación en Venezuela mediante el método de entrevistas con funcionarios policiales permite suponer que el castigo directo, de diversa intensidad, es claramente reconocido por los policías y se encuentra asociado a la devaluación moral y al escaso poder de reclamo de su destinatario (Monsalve Briceño, 2005). Dado que las víctimas usuales de estos castigos pertenecen a los sectores pobres y subordinados de la población, careciendo, por consiguiente, de poder de reclamo social, el castigo directo así aplicado implica menor riesgo de consecuencias negativas para los funcionarios policiales involucrados.

La atribución de una facultad directa de castigar mediante la violencia física, por parte de la policía, podría estar alimentada por la cesión de espacios de control por parte de otras agencias formales, para lo cual las percepciones de la población pueden ser cruciales. Los datos de otras investigaciones sugieren que la desconfianza en el sistema de control formal y la aceptación de medidas sustitutivas, al margen de la legalidad, podría ser un fenómeno bastante generalizado en América Latina. Una evaluación de actitudes de la población en seis ciudades centroamericanas concluyó en que solamente entre el $3 \%$ y el $11 \%$ de los encuestados estimaban que el sistema judicial funcionaba bien, así como entre el $21 \%$ y el $47 \%$ manifestaron acuerdo con la presencia de grupos armados de autodefensa (Rico, 2000).

\section{Vulnerabilidad y empoderamiento juvenil}

La literatura sobre la adolescencia y la juventud coincide en presentar a los representantes del tramo etario 12-18 años como un grupo poblacional vulnerable a la 
victimización y a la comisión delictiva. El concepto de exclusión se ha manejado tanto en el medio anglosajón como en el latinoamericano para explicar dicha vulnerabilidad, aunque en el primero sería visto como algo inevitable asociado a la dinámica social regular, mientras que en el segundo tendría que ver con procesos de injusticia y desigualdad. En la visión anglosajona, los adolescentes están en malas condiciones frente a los adultos para competir por un trabajo que proporcione ingresos lícitos, lo cual incrementa la dependencia de expectativas de coetáneos para mantener un estatus que es precario por los escasos ingresos y que generaría ansiedad frente al logro de metas convencionales, siendo que la presión hacia la desviación y la delincuencia disminuiría después de los 17 años, cuando se incrementa el acceso a fuentes legítimas de ingresos, se responde frente a expectativas de responsabilidad y madurez, disminuye la interacción con pares coetáneos, aumenta el riesgo de castigo legal e incluso aumentan las oportunidades ilícitas no violentas, vinculadas al fraude y la apropiación, con lo cual la visibilidad y persecución de la conducta ilícita tendería a disminuir (Birkbeck, 2006). En la visión latinoamericana la cuestión fundamental es la percepción de amenaza, carencia, desafiliación y desprecio que conlleva agresión y respuesta violenta hacia el otro (Zubillaga, 2007), en un contexto donde el mundo, representado como modelo universal de logro, más allá de las posibilidades de la clase social, aunado a privaciones y accidentes que exponen a los más carenciados, impiden la planificación y avance hacia el mundo adulto (Viscardi, 2011). Pese a una visión divergente, por cuanto en un caso los bloqueos y privaciones se ven como naturales y superables, mientras en el otro como producto de opresión social y sin salida, en ambas perspectivas destaca el debilitamiento y la minusvalía del joven, especialmente de género masculino, frente a quienes tienen poder, dominio y definen el control, asimetría que propendería a la generación de violencia y represión.

En otra sede se ha definido el empoderamiento como reconocimiento de derechos y reducción de asimetrías, así como la revaluación del individuo como sujeto moral y la reducción del desbalance de poder entre victimarios y víctimas, propugnando la integración al contexto normativo común (Gabaldón, 2007: 129-130). En el caso de la violencia extrema policial aplicada a los jóvenes, los victimarios son los policías y las víctimas, los jóvenes. Se hace necesario reducir esta disparidad de poder que se ha venido consolidando debido a la crisis de los controles informales benignos de tipo familiar y comunitario, por una parte, y a la falta de credibilidad y contracción de los mecanismos formales de justicia, por la otra. Los primeros facilitan contención e identidad, y los segundos, tratamiento moderado en el ejercicio de la coacción estatal.

El concepto de empoderamiento juvenil pasa por la atribución y el reconocimiento de identidades legítimas y toleradas a los jóvenes, sin esperar alcanzar la recuperación del control familiar y comunal o la ocupación efectiva del espacio del control social formal garantista por el otro, aspectos que resultan problemáticos a corto plazo. El fomento de identidades legítimas y toleradas entre los jóvenes supone su reconocimiento 
efectivo como sujetos morales, con capacidad de asumir responsabilidades y acumular respetabilidad. La adquisición de identidades legítimas y toleradas tiene una dimensión atributiva y una reductiva. La atributiva supone condiciones asociadas al prestigio personal y al reconocimiento por parte de los otros, y algunos factores asociados a esta dimensión son el empleo y los ingresos lícitos, la responsabilidad frente a los miembros de la comunidad, la energía creadora y la manifestación de conductas altruistas. La dimensión reductiva supone la minimización de la participación delictiva y de la ostentación del poder que, aparentemente, confiere la posesión y exhibición de armas de fuego, a lo cual deberían contribuir programas de intervención temprana y primaria y la aplicación de medidas de detección precoz que permitan contener la escalada delictiva. Ello supone también iniciativas para minimizar la confrontación y resistencia frente a la policía, para lo cual la eliminación de las armas en poder de los jóvenes resulta crucial. Todo ello debería redundar en la reducción de las oportunidades para la comisión de delitos violentos, así como de las condiciones que favorecen el castigo violento de la delincuencia (Gabaldón, 2007).

Los estudios venezolanos sobre la policía muestran mediante la investigación cualitativa que la devaluación moral del infractor puede ser pretexto o excusa para el uso excesivo de la fuerza o la aplicación directa del castigo (Gabaldón y Birkbeck, 1998; Monsalve Briceño, 2007) y mediante el uso de escalas, que dicha devaluación, en combinación con la percepción de respeto e influencia social según el estatus profesional, tiene incidencia en la disposición de aplicar niveles más elevados de fuerza física (Gabaldón y Birkbeck, 1996). Si, por consiguiente, el poder de reclamo social asociado a la respetabilidad moral disminuye la probabilidad de que la violencia sea usada contra el ciudadano, el empoderamiento juvenil se convierte en una prioridad, en un momento cuando los controles familiares y comunitarios que antaño brindaban protección bajo el manto de 'asumir la responsabilidad por el otro' han cedido y se requiere 'asumir la responsabilidad por sí mismo'. Todos los programas que contribuyan a incrementar este sentido de responsabilidad y a disminuir la sensación de extrañamiento deberían contribuir a la reducción de la coacción en los mecanismos de control social.

\section{Perspectivas}

La difusión de prácticas violentas, sea cual fuere su fuente, es percibida en la modernidad como desestabilizadora y disruptiva del orden social. Ello se aplica tanto a la violencia armada y compacta del Estado como a la violencia fragmentaria y atomizada en determinadas áreas urbanas o rurales. Algunas de estas formas resultan más visibles y publicitadas, otras permanecen en claroscuro y son menos tematizadas. Dado que en la sociedad contemporánea la condición para cualquier tema o problema social es la publicidad en los multimedia, en la medida en que la cobertura de la violencia fragmentaria es menor, no la percibimos como un verdadero problema. $Y$ sin 
embargo, allí está, cobrando su cuota de bajas y retroalimentando conductas que van generalizando y reforzando prácticas sociales.

La policía y los jóvenes transgresores son parte importante de este fenómeno de difusión de violencia fragmentaria, aunque de ninguna manera agotan su espectro. La policía se desplaza en una frontera porosa entre el control social formal e informal, pues si bien su capacidad para usar la coacción inmediata debería ser, dentro de los cánones legales, estrictamente instrumental y subordinada dentro de una organización de agencias múltiples, el ejercicio cotidiano de la coacción asume frecuentemente un carácter expresivo y autónomo frente al resto de las agencias de control social formal. La Ley Orgánica del Servicio de Policía y Cuerpo de Policía Nacional Bolivariana (Venezuela, 2009) enfatiza, entre los criterios para graduar el uso de la fuerza por parte de la policía, la intensidad en función de la conducta situacional de la persona y la abstención de emplear maltratos morales o su utilización como forma de castigo directo (art. 70). Sin embargo, el tránsito entre la prescripción legal y la práctica cotidiana requiere supervisión, entrenamiento y tiempo para modificar prácticas establecidas.

Los jóvenes, por otro lado, conforman una población especialmente vulnerable, debido a su subordinación a los adultos y, en general, a cualquier forma de autoridad. Cuando desafían a los adultos dotados de autoridad, entre quienes destacan los policías, particularmente a través de conductas delictivas que victimizan a estos funcionarios o a personas relacionadas, y sobre todo cuando los victimarios son miembros de grupos desarraigados, provenientes de zonas pobres, con carencias familiares y educacionales importantes, a lo que se añade la exhibición ostentosa y la utilización de armas de fuego como signos de poder, la imposición del control social puede revestir formas intensas de coacción. Si a esto se añade la precariedad de la legalidad formal y la generalización de estereotipos sobre grupos temibles que gozarían de impunidad legal, dado que los mecanismos de sanción jurídica no se activan o lo hacen en forma ineficaz, su vulnerabilidad como grupo podría aumentar y su castigo extremo podría normalizarse completamente, como sugieren los estudios, entrevistas y hasta los comentarios cotidianos de los funcionarios policiales. La investigación sobre los jóvenes transgresores, el uso de las armas y la policía ilustra bien esta vulnerabilidad y la escalada de un control social informal extremadamente coactivo. Comprender su extensión, significado y motivación es el primer paso para su minimización.

La coacción física ilegítima tiende a ser denunciada por los discursos morales de la criminología como abuso de poder (Birkbeck, 1996); sin embargo, ella también es una forma de control social, si se entiende por éste cómo la gente define y responde al comportamiento inaceptable y si se lo aborda como variable dependiente (Black, 1984). El control de la violencia social debe considerar, por consiguiente, no solo la que se manifiesta como infracción de normas legales, sino la que se usa en nombre del 
restablecimiento de dichas normas y se manifiesta con la convicción de que esas normas son inútiles para controlarla. La policía y los jóvenes tienen todavía mucho que enseñarnos en esta materia.

\section{Referencias}

Aguilar, Jeannette (2010). Jóvenes, pandillas y violencia en El Salvador, en Jóvenes, violencia y seguridad ciudadana. Caracas, Consejo General de Policía, pp. 49-65.

Antillano, Andrés (2012). Seguridad y política en la Venezuela bolivariana: la seguridad en el debate político venezolano entre 1998 y 2009. Espacio Abierto, 21, 4, pp. 701-726.

Black, Donald (1989). Sociological Justice. New York. Oxford University Press.

Black, Donald (1984). Social Control as a Dependent Variable, en Donald, Black (Ed.). Toward a General Theory of Social Control, Vol. I, Fundamentals. Orlando, Academic Press, pp. 1-36.

Black, Donald (1980). The Manners and Customs of the Police. San Diego. Academic Press.

Birkbeck, Christopher (2006). El significado de la adolescencia para la Criminología, en Guzmán Dálbora, José Luis y Serrano Maíllo, Alfonso (Eds.). Derecho Penal y Criminología como fundamento de la Política Criminal, Madrid, Dykinson, pp. 157169.

Birkbeck, Christopher (1996). La Criminología como discurso moral: los planteamientos sobre las causas de la delincuencia en Venezuela, 1950-1990, en Gabaldón, Luis Gerardo y Birkbeck, Christopher (Orgs.). Control Social y Justicia Penal en Venezuela, Mérida, Universidad de Los Andes, pp.37-68.

Brown, Stephen E., Finn-Aage Esbensen y Gilbert Geis (1991). Criminology. Explaining crime and its context. Cincinnati. Anderson Publishing.

Cano, Ignacio (2001). Policía, paramilitares y escuadrones de la muerte en América Latina, en Bodemer, Klaus, Kurtenbach, Sabine y Meschkat, Klaus (Eds.). Violencia y regulación de conflictos en América Latina, Caracas, Nueva Sociedad, pp. 219235.

Consultores 21 (2001). Informe sobre Estudio de Victimización. Ministerio de Justicia. Caracas.

De Roux, Gustavo (2001). Negociación con bandas juveniles urbanas. El caso de Cali, en Bodemer, Klaus, Kurtenbach, Sabine y Meschkat, Klaus (Eds.). Violencia y regulación de conflictos en América Latina. Caracas. Nueva Sociedad, pp.413-424.

Farrington, David (1996). The development of offending and antisocial behavior from childhood to adulthood, en Cordella, Peter y Siegel, Larry (Eds.). Contemporary Criminological Theory. Boston, Northeastern University Press, pp.107-120. 
Figueroa Ibarra, Carlos (1991). Guatemala: The Recourse to Fear, en Huggins, Martha K., (Ed.). Vigilantism and the State in Modern Latin America, Essays on Extralegal Violence. Nueva York, Praeger, pp. 73-83.

Gabaldón, Luis Gerardo (2013). La reforma policial en Venezuela: Lecciones aprendidas e implicaciones para las políticas públicas de seguridad ciudadana, Espacio Abierto_22, 3, pp. 667-679.

Gabaldón, Luis Gerardo (2007). Territorialidad, legitimidad y empoderamiento en la seguridad ciudadana y el control del delito en América Latina, Espacio Abierto, 16, 1, pp. 119-134.

Gabaldón, Luis Gerardo (1990). Control social y prevención del delito, en Aniyar de Castro, Lola, (Ed.). Criminología en América Latina. Roma, Unicri, 1990, pp. 91-102.

Gabaldón, Luis Gerardo (1987). Control social y criminología. Caracas, Editorial Jurídica Venezolana.

Gabaldón, Luis Gerardo (1982). La concepción marxista sobre la dominación y la legitimidad, Revista Cenipec, 7, pp. 9-13.

Gabaldón, Luis Gerardo, Benavides, David y Parra, Yasmely (2007). Victimización Delictiva y percepción de la Policía, en Gabaldón, Luis Gerardo y Antillano, Andrés (Eds.). La Policía Venezolana: Desarrollo Institucional y Perspectivas de Reforma al Inicio del Tercer Milenio, Vol. 1, Caracas: Comisión Nacional para la Reforma Policial, pp. 307-341.

Gabaldón, Luis Gerardo y Peraza, Manuel (2007). Consulta a Grupos Vulnerables, en Achkar, Soraya y Riveros, Amaylin, (Eds.). La Consulta Nacional sobre la Reforma Policial en Venezuela: una propuesta para el diálogo y el consenso. Caracas: Comisión Nacional para la Reforma Policial, pp. 439-478.

Gabaldón, Luis Gerardo y Suyín Serrano, Carla (con la colaboración de Monsalve, Yoana y Sanginés, Cristian) (2001). Violencia Urbana: perspectivas de jóvenes transgresores y funcionario policiales en Venezuela. Caracas. Universidad Católica Andrés Bello.

Gabaldón, Luis Gerardo y Birkbeck, Christopher (1998). Criterios situacionales de funcionarios policiales sobre el uso de la fuerza física, Capítulo Criminológico,_26, 2, pp. 99-132.

Gabaldón, Luis Gerardo y Birkbeck, Christopher (1996). Estatus social, comportamiento ciudadano y violencia policial: una evaluación actitudinal en policías venezolanos, Capítulo Criminológico, 24, 2, pp. 31-59.

Gabaldón, Luis Gerardo y Murúa, Mario (2010). Interacción policía-público: activación, respuesta y variables interpersonales y situacionales, en Antillano, Andrés (Comp.) Qué es, cómo se hace y para qué sirve el trabajo policial: Ensayos sobre desempeño y evaluación de la policía. Tomo II. Caracas, Consejo General de Policía, pp. 59-78.

Garrido, Vicente, Stangeland, Per y Redondo, Santiago (2001). Principios de Criminología. Valencia. Tirant Lo Blanch. 
Gottfredson, Michael y Hrischi, Travis (1992). A General Theory of Crime.

Stanford. Stanford University Press.

Hagan, John (1989). A power - control theory of gender and delinquency, en John Hagan, Structural Criminology, New Brunswick, Rutgers University Press, pp.145162.

Monsalve Briceño, Yoana (2007). Castigo policial y valoración moral del infractor, en Achkar, Soraya y Gabaldón, Luis Gerardo, (Eds.). Reforma policial: una mirada desde afuera y desde adentro. Caracas, Comisión Nacional para la Reforma Policial, pp. $175-180$.

Monsalve Briceño, Yoana (2005). Control social y castigo: percepción en funcionarios policiales venezolanos, Capítulo Criminológico, 33, 1, pp. 7-30.

Moreno Zapata, María Esperanza (2001). Impacto de la actuación de los integrantes del sistema penal de responsabilidad del adolescente en la fase de ejecución, en Cornieles, Cristóbal y Morais, María G. (Coords.). Segundo año de vigencia de la Ley Orgánica para la Protección del Niño y del Adolescente, Caracas. Universidad Católica Andrés Bello, pp. 277-305.

Pilliavin, Irving y Briar, Scott (1964). Police encounters with juveniles, American Journal of Sociology, 70, pp. 206-214.

Provea (2013). Situación de los Derechos Humanos en Venezuela. Informe Anual, EneroDiciembre 2013. Caracas. Programa Venezolano de Educación Acción en Derechos Humanos.

Provea (2006). Situación de los Derechos Humanos en Venezuela. Informe Anual, Octubre 2005-Septiembre 2006. Caracas. Programa Venezolano de Educación Acción en Derechos Humanos.

Provea (2001). Situación de los Derechos Humanos en Venezuela. Informe Anual, Octubre 2000-Septiembre 2001. Caracas. Programa Venezolano de Educación Acción en Derechos Humanos.

Rico, José María (Coord.) (2000). Seguridad Ciudadana en Centroamérica: Diagnóstico sobre la Situación. San José, Instituto Interamericano de Derechos Humanos.

Sanjuán, Ana María (2000). Democracia, ciudadanía y violencia en Venezuela, en Rotker, Susana, (Ed.). Ciudadanías del miedo. Nueva Sociedad. Caracas, pp. 81-93.

Sanjuán, Ana María (2013). La crítica situación de seguridad ciudadana en Venezuela. Características, causalidades, políticas y desafíos, en Basombrío, Carlos (Ed.). ¿A dónde vamos? Análisis de políticas públicas de seguridad en América Latina. Wilson Center, Washington, pp.297-347.

Serrano, Carla (1999). Análisis cualitativo de las respuestas a las preguntas abiertas de la Encuesta sobre Jóvenes y Armas de Fuego en Venezuela. Proyecto de Investigación Jóvenes y Armas de Fuego en Venezuela. Caracas, Universidad Católica Andrés Bello. 
Serrano, Carla, Perfetti, Erna y Martínez, John (2010). Implicaciones en la instrumentación del juicio educativo previsto en la Lopnna, en Jóvenes, violencia y seguridad ciudadana. Caracas, Consejo General de Policía, pp. 109-120.

Venezuela (2009). Ley Orgánica del Servicio de Policía y Cuerpo de Policía Nacional. G.O. n. 5.880 Extraordinario, 9 de abril de 2009.

Venezuela (2010). Encuesta Nacional de Victimización y Percepción de Seguridad Ciudadana. Documento Técnico. Consejo Nacional de Prevención y Seguridad Ciudadana e Instituto Nacional de Estadística.

Viscardi, Nilia (2011). Jóvenes infractores: biografías de la exclusión social en Uruguay, en Tavares dos Santos, José Vicente, Niche Teixeira, Alex y Russo, Mauricio (Orgs.) Violencia e Cidadania, Porto Alegre, UFRGS-Sulina, pp. 77-104.

West, W. Gordon (1984). Young Offenders and the State, Toronto, Butterworths.

Zubillaga, Verónica (2007). Los varones y sus clamores: los sentidos de la demanda de respeto y la lógica de la violencia entre jóvenes, Espacio Abierto, 16, 3, 577-608. 